\title{
Rubiscolytics: fate of Rubisco after its enzymatic function in a cell is terminated
}

\author{
Urs Feller ${ }^{1, *}$, Iwona Anders ${ }^{1}$ and Tadahiko Mae $^{2}$ \\ ${ }^{1}$ Institute of Plant Sciences, University of Bern, Altenbergrain 21, CH-3013 Bern, Switzerland \\ ${ }^{2}$ Graduate School of Agricultural Science, Tohoku University, 1-1 Tsutsumidori-Amamiyamachi, Aoba-ku, \\ Sendai 981-8555, Japan
}

Received 30 July 2007; Revised 24 August 2007; Accepted 14 September 2007

\section{Abstract}

Ribulose-1,5-bisphosphate carboxylase/oxygenase (Rubisco) is the predominant protein in photosynthesizing plant parts and the most abundant protein on earth. Amino acids deriving from its net degradation during senescence are transported to sinks (e.g. developing leaves, fruits). Rubisco catabolism is not controlled only by the overall sink demand. An accumulation of carbohydrates may also accelerate senescence and Rubisco degradation under certain conditions. Amino acids produced by proteolysis are rapidly redistributed in plants with proper source-sink relationships. In leaves of wheat plants with reduced sink capacity (e.g. sink removal, phloem interruption by steam girdling at the leaf base), Rubisco is degraded and free amino acids accumulate. They may be washed out in the rain during late senescence. In leaves of depodded soybeans, Rubisco is degraded and amino acids can be reutilized in these leaves for the synthesis of special vacuolar proteins in the paraveinal mesophyll (vegetative storage proteins). Nitrogen deriving from Rubisco degradation in older (senescing) leaves of annual crops is integrated to some extent again in newly synthesized Rubisco in younger leaves or photosynthesizing tissues of fruits. Finally, a high percentage of this nitrogen is accumulated in protein bodies (storage proteins). At the subcellular level, Rubisco can be degraded in intact chloroplasts. Reactive oxygen species may directly cleave the large subunit or modify it to become more susceptible to proteolysis. A metalloendopeptidase may play an important role in Rubisco degradation within intact chloroplasts. Additionally, the involvement of vacuolar endopeptidase(s) in Rubisco catabo-
\end{abstract}

lism (at least under certain conditions) was postulated by various laboratories.

Key words: Chloroplast, endopeptidase, nitrogen remobilization, phloem transport, proteolysis, Rubisco, stress, vacuole.

\section{Rubisco: the most abundant protein on earth}

Ribulose-1,5-bisphosphate carboxylase/oxygenase (Rubisco; EC 4.1.1.39) is present at very high levels in photosynthesizing cells and must therefore be considered as the most abundant protein in the world (Ellis, 1979). Rubisco is the predominant protein in leaves of $\mathrm{C}_{3}$ plants and may contribute up to $50 \%$ to the soluble leaf proteins (Spreitzer and Salvucci, 2002) and 20-30\% of total leaf nitrogen (Evans and Seemann, 1989; Makino 2003; Kumar et al., 2002). In leaves of $C_{4}$ plants, Rubisco still contributes $\sim 30 \%$ to the soluble proteins (Sugiyama et al., 1984) and 5-9\% of total leaf nitrogen (Sage et al., 1987; Makino et al., 2003). Rubisco, phosphoenolpyruvate (PEP) carboxylase, and pyruvate orthophosphate dikinase are the most abundant soluble proteins in leaves of $\mathrm{C}_{4}$ plants and may contribute together nearly the same percentage to the soluble leaf proteins as Rubisco alone in leaves of $\mathrm{C}_{3}$ plants (Sugiyama et al., 1984; Sage et al., 1987; Makino et al., 2003). The large subunit of Rubisco is easily detectable on stained gels from $\mathrm{C}_{3}$ or $\mathrm{C}_{4}$ plants (Fig. 1). Considering the high percentage of leaf nitrogen bound in Rubisco, it becomes evident that this enzyme is, besides its function in the assimilation of inorganic carbon, highly relevant for the nitrogen budget of a plant. This review is focused on senescence, Rubisco degradation, and the reutilization of Rubisco nitrogen within the plant.

* To whom correspondence should be addressed. E-mail: urs.feller@ips.unibe.ch 

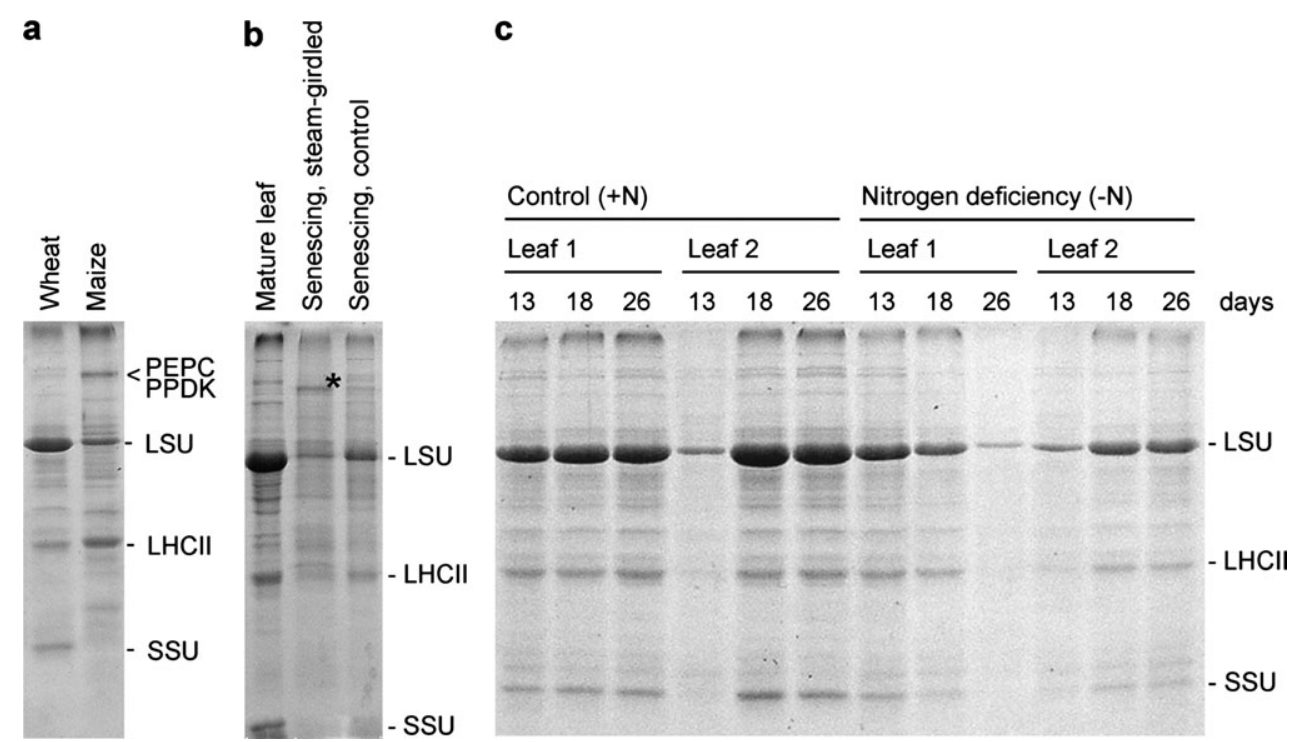

Fig. 1. Rubisco large (LSU) and small (SSU) subunits on SDS-polyacrylamide gels loaded with wheat and maize leaf extracts (a), effect of steam girdling the petiole on the polypeptide pattern in French bean leaves (b), and influence of the availability of inorganic nitrogen in the culture medium on Rubisco levels in wheat leaf extracts (c). (a) The Rubisco LSU is easily detectable in wheat and maize samples ( $\sim 53 \mathrm{kDa})$. The strong band in the range 95-110 kDa in the maize sample contains phosphoenolpyruvate carboxylase (PEPC) and pyruvate phosphate dikinase (PPDK). (b) French bean plants were grown on a medium with a low nitrate concentration. The phloem was interrupted in the petiole of the first trifoliate leaf of some plants by steam girdling. The lanes were loaded with an equal percentage $(0.2 \%)$ of a leaflet. A new band $(*)$ appeared in extracts from steam-girdled leaves, but not or only weakly in extracts from leaves with an intact phloem through the petiole. (c) Wheat seeds were germinated on wet tissue paper in darkness for $2 \mathrm{~d}$ and then transferred to a light/dark cycle $(14 \mathrm{~h}$ light $/ 10 \mathrm{~h}$ darkness). The wheat plants grew on deionized water until day 13 and were then transferred to a nutrient medium lacking mineral nitrogen $(-\mathrm{N})$ or to the same medium supplemented with $5 \mathrm{mM} \mathrm{NH}_{4} \mathrm{NO}_{3}(+\mathrm{N})$. Samples were collected at day 13 (transfer from deionized water to nutrient medium with or without nitrogen), day 18, and day 26 after imbibition. The lanes were loaded with an equal percentage $(0.6 \%)$ of a leaf, allowing a direct comparison.

\section{Reutilization of Rubisco nitrogen in whole plants}

After fulfilling the enzymatic functions, Rubisco is degraded and becomes a major internal nitrogen source. Senescence and Rubisco degradation already occur during the early phases of vegetative growth (Fischer and Feller, 1994). The nitrogen remobilized during Rubisco degradation in the oldest leaves can be translocated to young leaves, and later to even younger leaves or to maturing fruits. A high percentage of the nitrogen present in whole cereal or legume plants is accumulated finally in the protein bodies of mature seeds. Although the degradation of chlorophyll is in general the most obvious senescence symptom, chlorophyll nitrogen remains in the form of colourless chlorophyll catabolites in the vacuole of senescing leaf cells and is not exported to other plant parts (Hörtensteiner and Feller, 2002). Rubisco degradation and chlorophyll catabolism are often well correlated and represent major senescence symptoms, but under certain conditions these two processes may be partially or fully uncoupled (e.g. in stay-green genotypes), as discussed elsewhere (Thomas et al., 2002; Hörtensteiner and Feller, 2002; Hörtensteiner, 2006).

Senescence and protein remobilization in maturing cereals are well organized and controlled on the wholeplant level (Fig. 2). Senescence in wheat progresses from the lowest (oldest) to the uppermost (youngest) leaves, and within the leaves senescence starts at the tip and progresses towards the base and the leaf sheath (Fig. 2a). In corn, senescence also starts at the leaf tip and expands as a V-shaped area towards the leaf base (Fig. 2c). In contrast to wheat, the uppermost (youngest) leaf is not the last one to senesce (Fig. 2b, d). In corn, senescence and protein remobilization start before anthesis in the oldest leaves. During grain maturation, senescence also starts at the top of the plant and the last green leaves are near or slightly above the ear(s) (Feller et al., 1977). From these facts it becomes evident that the age of the leaf is not, or not only, relevant and that the position of major sinks (developing grains) is important in this context.

A further redistribution of nitrogen occurs within the wheat ear. Glumes (containing glume, lemma, and palaea) contain Rubisco and are photosynthetically active after ear emergence (Wirth et al., 1977; Feller, 1978). Glumes also senesce in a later phase of maturation and Rubisco nitrogen becomes available for export again (Fig. 2e). Furthermore, the maturing wheat grains contain a photosynthetically active tissue, the cross cells (Fig. 2g). This peripheral layer in the caryopses also senesces at the end of the maturation period (Fig. 2f). The cross cells and the glumes may reassimilate $\mathrm{CO}_{2}$ released by respiration in the inner parts of the grain (Wirth et al., 1977; Watson and Duffus, 1991; Gebbing and Schnyder, 2001; Tambussi et al., 2007). The $\mathrm{CO}_{2}$ assimilation within the ear may be 

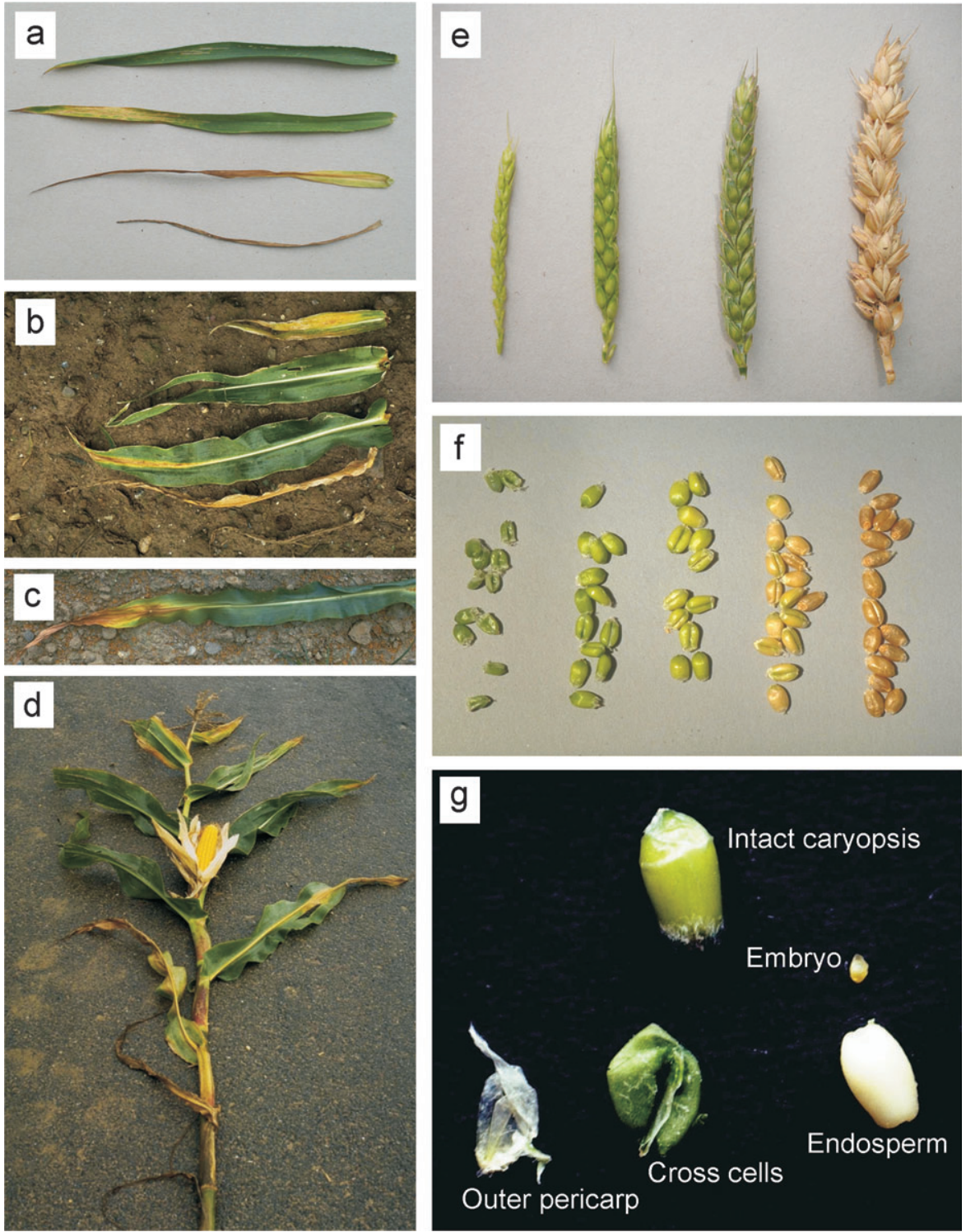

Fig. 2. Loss of photosynthetic capacity in maize and wheat. A picture of the four uppermost leaves of wheat taken shortly after anthesis is shown in (a) (arranged according to their position on the plant). Leaves 1, 4, 7, 10, and 13 from the top of corn (early grain filling period) are shown in (b). The progress of senescence within a leaf and in the whole corn plant is shown in (c) and (d), respectively. Wheat ears 1 week before ear emergence, at ear emergence, at anthesis, and at maturity are shown from left to right in (e). Wheat grains collected at weekly intervals from anthesis (left) to maturity (right) are documented in (f). A grain was dissected 2 weeks after anthesis to illustrate the photosynthetically active (green) cross cells (g).

especially relevant under drought stress (Martinez et al., 2003; Tambussi et al., 2005). In legumes and other dicotyledonous plants, a redistribution of nitrogen from the carpels and from the seed coat to the storage tissues in the seeds can also be observed (Feller, 1990, and references therein). While Rubisco is the predominant protein in green (photosynthesizing) plant parts, storage proteins in the protein bodies are the most abundant proteins in the storage tissues.

The nitrogen fluxes into and out of various parts of wheat and corn plants are schematically shown in Fig. 3 (Feller et al., 1977; Feller and Erismann, 1978; Mae, 2004). Leaf senescence is not restricted to the maturation phase, since the oldest leaves already senesce during the early phases of vegetative growth (Fischer and Feller, 1994). Nitrogen may enter expanding leaves via the phloem or via the xylem (Feller and Fischer, 1994). After the sink-to-source transition, the flux of nitrogen into the leaves is restricted to the xylem. Reduced nitrogen may be exported throughout the life span of a leaf via the phloem, but this export becomes most important during the rapid degradation of chloroplast proteins after the onset of senescence (Feller, 1990; Crafts-Brandner et al., 1996, 1998). In mature leaves, amino acids entering a leaf in the transpiration stream may be transferred to the phloem and exported again without being taken up into mesophyll 


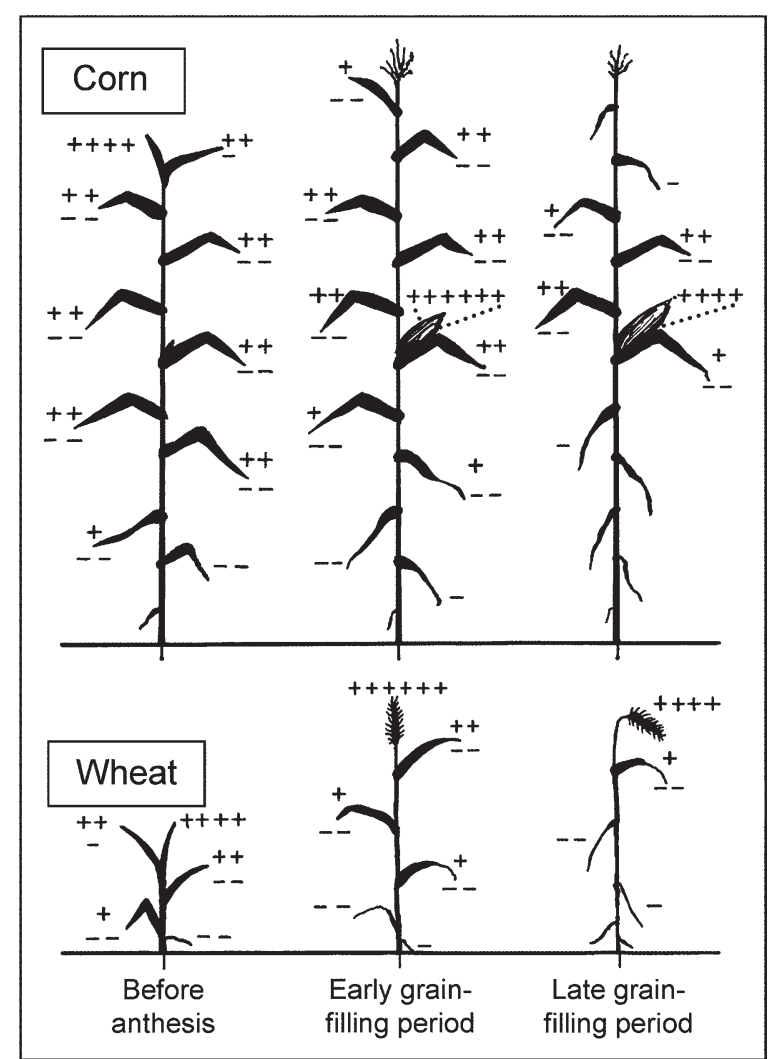

Fig. 3. Schematic overview of nitrogen transport into and out of maize and wheat leaves. Minor $(+)$ and major $(++++++)$ fluxes into a plant part are indicated as well as minor $(-)$ and major $(--)$ nitrogen fluxes out of the leaves for three developmental stages.

cells (Feller and Fischer, 1994, and references therein). Nitrate on the other hand is not mobile in the phloem, and the nitrogen of this compound may be exported after assimilation in the mesophyll cells. Rubisco is synthesized at a high rate during leaf expansion, is usually turned over very slowly in mature leaves, and its net degradation starts shortly after full leaf expansion, when Rubisco becomes a major nitrogen source for other plant parts (Mae, 2004).

\section{Rubisco degradation and redistribution of Rubisco nitrogen under altered source-sink relationships}

Amino acids deriving from Rubisco catabolism are in general exported via the phloem, avoiding an accumulation of free amino acids in the senescing plant parts (Fröhlich and Feller, 1992). However, altered source-sink relationships affect senescence and protein catabolism in leaves on one hand and the export of the amino acids deriving from proteolysis on the other hand (Feller and Fischer, 1994). After panicle or ear removal, assimilates may be allocated to alternative sinks (e.g. tillers), avoiding accumulation in the source leaves (Feller and Fischer, 1994, and references therein; Nakano et al., 1995). When the export of assimilates from cereal leaves is interrupted, the degradation of Rubisco is accelerated and the content of free amino acids reaches high levels (Fröhlich and Feller, 1992; Feller and Fischer, 1994; Parrott et al., 2005). Under field conditions, accumulated free amino acids may be washed out from the leaves in the rain during a late senescence phase (Debrunner and Feller, 1995; Debrunner et al., 1999). In contrast to potassium and other inorganic ions, the leakage of amino acids is usually not relevant in plants with proper source-sink relationships. From these results, it becomes evident that the net degradation of Rubisco is not only controlled by the demand for amino acids in growing plant parts. Loss of photosynthetic capacity, net degradation of Rubisco and PEP carboxylase, and senescence are accelerated in maize after ear removal (Crafts-Brandner and Poneleit, 1987). The fact that the response to ear removal in cereals depends on the species and even on the genotype supports the assumption that the control of Rubisco catabolism is complex (Crafts-Brandner and Poneleit, 1987; Nakano et al., 1995).

In leaves of depodded soybean plants, Rubisco is finally also degraded and a special set of proteins is synthesized (Wittenbach, 1982; Franceschi et al., 1983; CraftsBrandner and Egli, 1987). These newly synthesized polypeptides represent vegetative storage proteins and are located in the vacuole of the paraveinal mesophyll (Franceschi and Giaquinta, 1983; Klauer et al., 1996). The $94 \mathrm{kDa}$ vegetative storage protein in soybean has lipoxygenase activity (Tranbarger et al., 1991). The paraveinal mesophyll may act in intact plants as a buffer between the mesophyll (production of amino acids) and the phloem (export of amino acids from the leaf), as suggested by Franceschi and Giaquinta (1983). In addition to these predominant vegetative storage proteins, several other proteins accumulate in soybean leaves after fruit removal (Crafts-Brandner and Salvucci, 1994; Salvucci and Crafts-Brandner, 1995, and references therein). A Rubisco complex protein represents an interesting polypeptide in this context (Crafts-Brandner and Salvucci, 1994). An insoluble complex is formed in vitro when this polypeptide (30 $\mathrm{kDa}$ subunits) and Rubisco are incubated in a 1:1 ratio by weight, while the complex is soluble when one of the components is present in a several-fold excess. Furthermore, it has been demonstrated that this Rubisco complex protein is located in the cytosol and not in the plastids (Crafts-Brander and Salvucci, 1994). The function of this polypeptide in intact cells is so far unknown. After pod removal, a $28 \mathrm{kDa}$ pod storage protein accumulates in newly formed pods of French bean plants, indicating that special proteins are also produced in young fruits after the removal of the major sinks (Zhong et al., 1997). It must be borne in mind that in depodded legume plants, leaf senescence and net Rubisco degradation may be delayed as compared with intact control 
plants (Nakano et al., 2000). The findings mentioned above indicate that in leaves of depodded soybean and other legume plants, amino acids deriving from Rubisco degradation may be incorporated into newly synthesized special proteins. New proteins may accumulate in various organs, in various cell types, and in various subcellular compartments.

The production of new polypeptides is also initiated in French bean leaves after interrupting the phloem in the petiole by steam girdling (Fig. 1b). This finding supports the hypothesis that the limited export from leaves of plants with a reduced sink capacity (e.g. after depodding) plays a key role in this context.

\section{Levels of Rubisco and Rubisco fragments under environmental stress}

The catabolism of Rubisco depends on a series of endogenous and environmental factors (Nooden et al., 1997; Demirevska-Kepova and Feller, 2004; MarínNavarro and Moreno, 2006). Only some examples for abiotic and biotic stress effects can be summarized here.

Nitrogen limitation causes an accelerated senescence in the oldest leaves of young bean (Crafts-Brandner et al., 1996) and wheat (Crafts-Brandner et al., 1998) plants. Rubisco is lost earlier in leaves of nitrogen-starved plants than in those of control plants. Transcript levels of nuclear-encoded stromal enzymes as well as their protein levels decline more rapidly under nitrogen starvation than in control plants. The effect of inorganic nitrogen in the culture medium on Rubisco levels is illustrated in Fig. 1c. After germination of wheat, nitrogen is available from the hydrolysis of storage proteins in the endosperm, allowing the proper development of the first leaf. If inorganic nitrogen is present in the nutrient medium, the level of Rubisco in the first leaf is maintained over many days and the level in the second (expanding) leaf increases to a high level. Under nitrogen deficiency, the Rubisco level declines in the first leaf and increases moderately in the second leaf. This pattern illustrates the reutilization of amino acids deriving from Rubisco degradation in the first leaf and the acceleration of leaf senescence under nitrogen deficiency. Rubisco fragments are usually not detectable on immunoblots with samples of extracts from senescing leaves of control or nitrogen-starved plants, indicating that the further hydrolysis of the fragments occurs rapidly. The amino acids produced by the degradation of Rubisco and other chloroplast proteins can be reutilized in other plant parts after transport via the phloem, allowing the growth of sink organs even under strong nitrogen limitation (Feller and Fischer, 1994).

Light is important for the net degradation of Rubisco (Feller and Fischer, 1994). Dark-induced senescence is frequently used as a model system, but under these conditions energy becomes limiting (low carbohydrate level) and protein catabolism may partially differ from that in illuminated leaves (initially high carbohydrate level). In wheat leaves, senescence and the net degradation of stromal proteins including Rubisco are accelerated by a depletion as well as by an accumulation of carbohydrates (Herrmann and Feller, 1998; Parrott et al., 2005: Thoenen et al., 2007).

Extreme climatic conditions (e.g. heat, drought, and waterlogging) are important stress factors for plants (Herrmann and Feller, 1998; Demirevska-Kepova and Feller, 2004). Elevated temperature can accelerate protein degradation in leaf segments (Demirevska-Kepova et al., 2005). It is interesting to note that a Rubisco fragment slightly smaller than the intact large subunit accumulates in wheat leaf segments incubated in the light in the absence of external $\mathrm{CO}_{2}$ (Herrmann and Feller, 1998; Thoenen et al., 2007).

Biotic stress (e.g. infection of plants by micro-organisms) may induce or accelerate senescence. Victorin, a fungal toxin, induces senescence and Rubisco fragmentation in oats (Navarre and Wolpert, 1999). The first 14 amino acids from the $\mathrm{N}$-terminus of the large subunit of Rubisco have been cleaved in oat leaf segments exposed to victorin for $4 \mathrm{~h}$ in darkness, while no such fragmentation could be observed in controls incubated under the same conditions in the absence of victorin. This cleavage of Rubisco is sensitive to E-64 (an inhibitor of sulphydryl endopeptidases). Navarre and Wolpert (1999) reported that victorin causes multiple effects in plant cells and might induce a signal cascade. The sequence of events leading to cell death after such fungal infections is not yet clear.

\section{Fate of Rubisco at the subcellular level}

During the past two decades, impressive numbers of genes encoding different types of plant peptide hydrolases or proteins with similarities to peptide hydrolases have been described by various groups (Schaller and Ryan, 1995; Shanklin et al., 1995; Buchanan-Wollaston, 1997; Bhalerao et al., 2003; Buchanan-Wollaston et al., 2003). The peptide hydrolases belong to different classes and are located in defined subcellular compartments. The functions of many of these peptide hydrolases have not yet been identified. The expression of genes encoding peptide hydrolases alters during senescence. The abundance of some mRNAs for peptide hydrolases strongly increases during this final phase of leaf development (Bhalerao et al., 2003; Buchanan-Wollaston et al., 2003). The question of whether and how these peptide hydrolases might be involved in the catabolism of Rubisco and other plastidial proteins is not yet satisfactorily answered. It is not only enzymes located inside the plastids that may 
contribute to the degradation of Rubisco, as suggested by various laboratories (Yoshida and Minamikawa, 1996; Guiamét et al., 1999; Thoenen et al., 2007).

Enzymatically active Rubisco is located in the stroma. Caution is recommended when using isolated chloroplasts as an experimental system, since contaminating endopeptidases of vacuolar origin may act on stromal proteins after chloroplast rupture (Miyadai et al., 1990). Treatment of the isolated chloroplasts with thermolysin (Miyadai et al., 1990) or the reisolation of intact chloroplasts after incubation of the samples (Mitsuhashi et al., 1992; Roulin and Feller, 1997, 1998a) may be suitable to avoid such artefacts. The predominant stromal protein Rubisco can be degraded in intact chloroplasts (Mitsuhashi et al., 1992; Desimone et al., 1996, 1998; Roulin and Feller, 1997, 1998a; Ishida et al., 1998; Zhang et al., 2007). Several exo- and endopeptidases are located in plastids (Adam and Clarke, 2002). A metalloendopeptidase is able to degrade the large subunit of Rubisco (Bushnell et al., 1993; Roulin and Feller, 1998a). Chelators (e.g. EDTA), which are often standard constituents of chloroplast isolation and incubation media, can inhibit the degradation of Rubisco in darkness. This inhibition is reversible by the removal of EDTA and the addition of zinc in the micromolar range and of magnesium in the millimolar range, strongly supporting the hypothesis that a metalloendopeptidase is involved (Roulin and Feller, 1998a). The $\mathrm{N}$-terminus was still present in the Rubisco large subunit fragments produced during the incubation of isolated chloroplasts, indicating that the first cut(s) occurred near the C-terminus (Roulin and Feller, 1998a; Ishida et al., 1999). A $44 \mathrm{kDa}$ fragment of the large subunit of Rubisco missing the $\mathrm{N}$-terminus was detected after the incubation of chloroplast lysates in darkness (Kokubun et al., 2002). This finding and the observations mentioned above suggest that different mechanisms for the degradation of Rubisco exist in plastids. Carbamylation and substrate binding of Rubisco may still be functional after limited proteolysis, although the catalytic activity may be lost (Gutteridge et al., 1986).

The degradation of Rubisco in intact chloroplasts can be achieved, initiated, or accelerated by reactive oxygen species (Desimone et al., 1996; Ishida et al., 1997; Stieger and Feller, 1997; Roulin and Feller, 1998b). It has been demonstrated that $\mathrm{Fe}^{2+}$ ions catalyse a site-specific cleavage of the large subunit of Rubisco near the catalytic centre (Luo et al., 2002). The in vivo fragmentation of the large subunit of Rubisco has been reported recently for cucumber leaf discs incubated in the light under chilling conditions (Nakano et al., 2006).

The sensitivity of enzyme proteins to proteolysis depends on the actual conditions in the relevant compartment (Feller, 2004). The $\mathrm{pH}$ value as well as solute concentrations may affect protein catabolism. Rubisco is protected against proteolytic degradation under catalytic conditions (Houtz and Mulligan, 1991) or in the presence of an inhibitor (reaction intermediate analogue) binding to the active site in the large subunit (Mulligan et al., 1988; Khan et al., 1999). Such interactions may allow a finetuning of the degradation. Rubisco can be present in an active (carbamylated) or an inactive form (Spreitzer and Salvucci, 2002). CND41, a DNA-binding aspartic protease in plastids, can degrade Rubisco and may play a role in senescence and Rubisco nitrogen remobilization (Kato et al., 2004). These authors have shown that active (carbamylated) Rubisco is less sensitive to this protease than the inactive form. Already moderately elevated temperatures negatively affect the activation of Rubisco by Rubisco activase (causing a lower percentage of carbamylated molecules) and may, as a consequence, also alter the susceptibility of Rubisco to attack by certain proteases (Feller et al., 1998).

Although often no Rubisco fragments are detected in naturally senescing leaves, typical breakdown products may accumulate in leaves or leaf segments under certain conditions (Hildbrand et al., 1994; Nakano et al., 2006; Thoenen et al., 2007). Under hypoxia or anoxia, a strong band becomes visible on gels (SDS-PAGE) below the large subunit of Rubisco (Hildbrand et al., 1994). $\left[{ }^{35} \mathrm{~S}\right]$ Methionine present in the incubation medium is not incorporated into this band, suggesting that the polypeptide is not synthesized de novo. On the other hand, this polypeptide cross-reacts with antibodies raised against the large subunit of Rubisco, indicating that this band is a breakdown product of Rubisco. From more recent experiments with antibodies raised against the $\mathrm{C}$ - and N-terminus of the large subunit of Rubisco (Fig. 4), it became evident that under these conditions the $\mathrm{N}$-terminus is removed and the C-terminus is still present. Two fragments of $\sim 50 \mathrm{kDa}$ and $40 \mathrm{kDa}$ become visible on blots with antibodies directed against the C-terminus. The larger (but not the smaller) fragment also reacts with antibodies against amino acids 9-28 from the N-terminus, while both fragments are not detected with antibodies raised against the first 25 amino acids from the $\mathrm{N}$ terminus. These results document that both fragments lack the N-terminus. These fragments are similar to those reported by Yoshida and Minamikawa (1996). Under hypoxia, the small subunit of Rubisco is well maintained, although a portion of most large subunit molecules is removed (Hildbrand et al., 1994). The removal of an Nterminal portion has also been detected in wheat leaf segments incubated under conditions causing a low carbohydrate level (Thoenen et al., 2007). The formation of such fragments is inhibited by E-64 (an inhibitor of cysteine endopeptidases). Furthermore, it could be shown that this cleavage occurs when the large subunits are still integrated together with the small subunits in the Rubisco holoenzyme (Thoenen et al., 2007). This type of fragmentation was not observed in isolated pea chloroplasts. The 

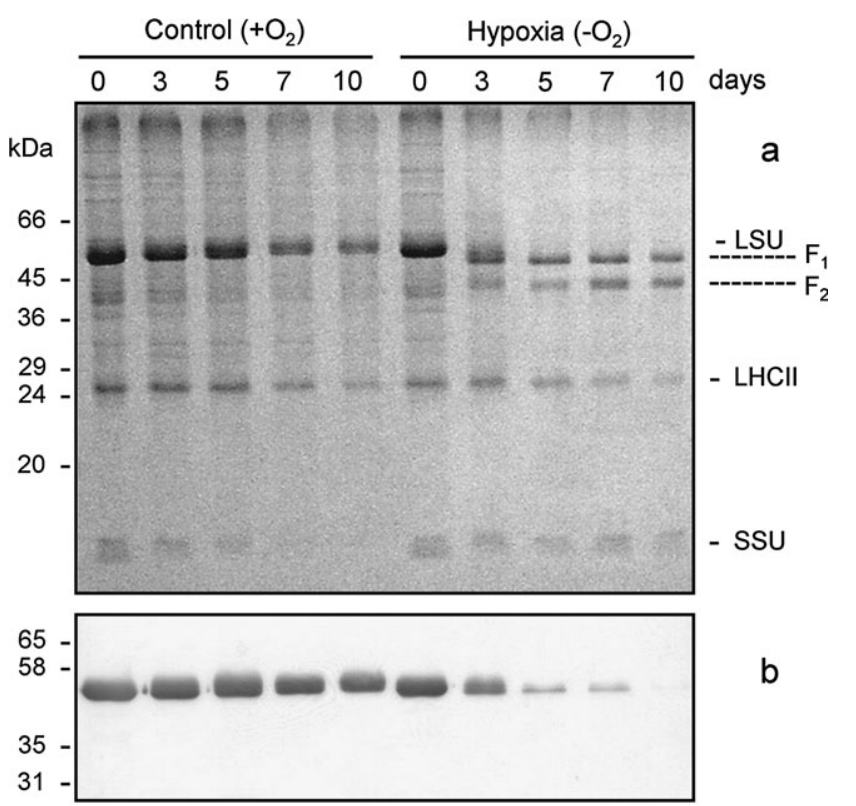

b
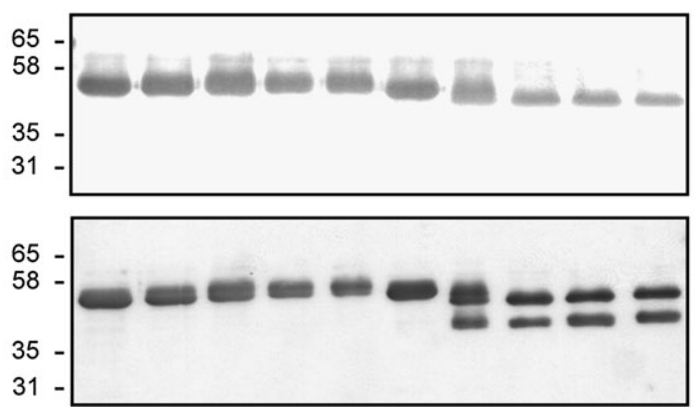

d

Fig. 4. Fragmentation of the large subunit of Rubisco in bean leaves incubated under hypoxia in darkness. Detached bean leaves were incubated in darkness for $0,3,5,7$, and $10 \mathrm{~d}$ either floating on deionized water $\left(+\mathrm{O}_{2}\right)$ or submerged in deionized water $\left(-\mathrm{O}_{2}\right)$. Extracts were analysed by SDS-PAGE with an equal percentage $(0.2 \%)$ of a leaf loaded per lane. The stained gel with the fragments $F_{1}$ and $F_{2}$ is shown in (a). Specific antibodies raised in rabbits against a synthetic version of the first 25 amino acids from the N-terminus of the large subunit from spinach Rubisco (b), against a synthetic version of amino acids 9-28 from the large subunit of wheat Rubisco (c), or against a synthetic version of a sequence near the C-terminus (amino acids 425-440) of the large subunit of Rubisco from wheat (d) were used to develop the immunoblots.

finding reported by Zhang et al. (2006) that a $50 \mathrm{kDa}$ fragment of Rubisco is produced in crude leaf extracts but not in chloroplast lysates is consistent with the hypothesis that extraplastidial enzymes degrade Rubisco in a manner different from the intraplastidial peptide hydrolases. It appears likely that the observed extraplastidial cleavage is caused by a vacuolar cysteine endopeptidase, while in isolated plastids other types of peptide hydrolases (e.g. metalloendopeptidases) or a direct fragmentation by reactive oxygen species are involved in the degradation of Rubisco.

The evidence for the involvement of vacuolar peptide hydrolases in Rubisco degradation raises the question of how the plastidial substrate protein (Rubisco) may become accessible to the vacuolar enzyme(s) separated by several membranes from the stroma (Yoshida and Minamikawa, 1996; Thoenen et al., 2007). It has been proposed that chloroplasts (Minamikawa et al., 2001) or spherical bodies deriving from chloroplasts and containing stromal proteins but not thylakoid components (Chiba et al., 2003) reach the vacuole for the final degradation of the chloroplast constituents. Guiamét et al. (1999) reported that, in leaves of wild-type French bean, globules with lipophilic contents are released from the chloroplasts into the cytosol (and perhaps later into the vacuole) during senescence, while these globules are absent from leaf cells in a stay-green genotype. Such lipophilic globules are the counterpart to the hydrophilic spherical bodies and may be involved in the degradation of pigments or membrane proteins rather than of stromal enzymes. The ricinosomes, organelles containing high levels of sulphydryl endopeptidase precursor, must be considered as important compartments involved in the increase of sulphydryl endopeptidase activity and of the rapid net protein degradation during senescence (Gietl and Schmid, 2001). The question as to what extent Rubisco is degraded intraplastidially and extraplastidially is still open and represents a challenge for future research.

\section{Conclusions}

Rubisco is degraded in leaves of intact plants during natural senescence as well as under various stress conditions. Rubisco nitrogen can be exported from senescing organs in the form of amino acids or peptides via the phloem, allowing the supply of growing plant parts. However, the net degradation of Rubisco is not always well correlated with the export of nitrogen from the leaves, since free amino acids may accumulate to high levels or may be incorporated in the same organ into newly synthesized proteins in other cells or other subcellular compartments. The question of how the net degradation of Rubisco is controlled remains open. There is not necessarily a switch allowing the initiation of Rubisco degradation. The opposite situation appears possible: the degradation of Rubisco might be the default pathway in the case of a metabolic disorder and might be initiated by a series of internal and external factors influencing leaf metabolism and interactions between organs. If so, then the question would be: which conditions must be fulfilled to maintain the Rubisco level prior to senescence?

Several laboratories presented good evidence that there is not one well-defined pathway for Rubisco degradation with well-defined proteolytic events. Depending on the actual conditions, reactive oxygen species may directly cleave the polypeptide chain, or plastidial or vacuolar enzymes may act on this stromal protein with or without prior modification. The concentrations of solutes 
interacting with Rubisco may affect its susceptibility to proteolytic attack and allow a fine-tuning of the net degradation rate. From the results available today, it appears likely that under photoinhibitory conditions and when carbohydrates are available in excess the degradation inside the plastids plays a major role, and that under energy deficiency (low carbohydrate levels) vacuolar endopeptidases may come into play earlier. Caution is recommended when generalizing mechanisms of Rubisco catabolism.

The following questions remain to be addressed in future experiments. (i) How is the remobilization of Rubisco nitrogen controlled in vivo? (ii) Which enzymes are involved in which phase of its catabolism? (iii) Which steps are located in which subcellular compartments? (iv) Is the native Rubisco protein degraded or are modifications necessary prior to proteolysis?

\section{Acknowledgements}

The work reported here was supported in part by the Swiss National Science Foundation (NCCR Climate and SCOPES Project DILPA). Antibodies against a synthetic version of the first 25 amino acids from the N-terminal region of the large subunit from spinach Rubisco were kindly provided by R Houtz and M Mulligan. The authors thank C Reynolds for improving the English of the manuscript.

\section{References}

Adam Z, Clarke AK. 2002. Cutting edge of chloroplast proteolysis. Trends in Plant Science 7, 451-465.

Bhalerao R, Keskitalo J, Sterky F, et al. 2003. Gene expression in autumn leaves. Plant Physiology 131, 1-13.

Buchanan-Wollaston V. 1997. The molecular biology of senescence. Journal of Experimental Botany 48, 181-199.

Buchanan-Wollaston V, Earl S, Harrison E, Maths E, Navabpour S, Page T, Pink D. 2003. The molecular analysis of leaf senescence-a genomics approach. Plant Biotechnology Journal 1, 3-22.

Bushnell TP, Bushnell D, Jagendorf AT. 1993. A purified zinc protease of pea chloroplasts, EP1, degrades the large subunit of ribulose-1,5-bisphosphate carboxylase/oxygenase. Plant Physiology 103, 585-591.

Chiba A, Ishida H, Nishizawa NK, Makino A, Mae T. 2003. Exclusion of ribulose-1,5-bisphosphate carboxylase/oxygenase from chloroplasts by specific bodies in naturally senescing leaves of wheat. Plant and Cell Physiology 44, 914-921.

Crafts-Brandner SJ, Egli DB. 1987. Sink removal and leaf senescence in soybean. Cultivar effects. Plant Physiology 85, 662-666.

Crafts-Brandner SJ, Hölzer R, Feller U. 1998. Influence of nitrogen deficiency on senescence and the amounts of RNA and proteins in wheat leaves. Physiologia Plantarum 102, 192-200.

Crafts-Brandner SJ, Klein RR, Klein P, Hölzer R, Feller U. 1996. Coordination of protein and mRNA abundances of stromal enzymes and abundances of the Clp protease subunits during senescence of Phaseolus vulgaris (L.) leaves. Planta 200, $312-318$.
Crafts-Brandner SJ, Poneleit CG. 1987. Effect of ear removal on $\mathrm{CO}_{2}$ exchange and activities of ribulose bisphosphate carboxylase/oxygenase and phosphoenolpyruvate carboxylase of maize hybrids and inbred lines. Plant Physiology 84, 261-265.

Crafts-Brandner SJ, Salvucci ME. 1994. The Rubisco complex protein-a protein-induced by fruit removal that forms a complex with ribulose-1,5-bisphosphate carboxylase/oxygenase. Planta 194, 110-116.

Debrunner N, Feller U. 1995. Solute leakage from detached plant parts of winter wheat: influence of maturation stage and incubation temperature. Journal of Plant Physiology 145, 257-260.

Debrunner N, von Lerber F, Feller U. 1999. Solute losses from various shoot parts of field-grown wheat by leakage in the rain. In: Anaç C, Martin-Prével P, eds. Improved crop quality by nutrient management. Dordrecht: Kluwer Academic Publishers, 131-134.

Demirevska-Kepova K, Feller U. 2004. Heat sensitivity of Rubisco, Rubisco activase and Rubisco binding protein in higher plants. Acta Physiologiae Plantarum 26, 103-114.

Demirevska-Kepova K, Hölzer R, Simova-Stoilova L, Feller U. 2005. Heat stress effects on Rubisco, Rubisco binding protein and Rubisco activase in wheat leaves. Biologia Plantarum 49, $521-525$

Desimone M, Henke A, Wagner E. 1996. Oxidative stress induces partial degradation of ribulose-1,5-bisphosphate carboxylase/oxygenase in isolated chloroplasts of barley. Plant Physiology 111, 789-796.

Desimone M, Wagner E, Johanningmeier U. 1998. Degradation of active-oxygen modified ribulose-1,5-bisphosphate carboxylase/ oxygenase by chloroplastic proteases requires ATP-hydrolysis. Planta 205, 459-466.

Ellis RJ. 1979. The most abundant protein in the world. Trends in Biochemical Sciences 4, 241-244.

Evans JR, Seemann JR. 1989. The allocation of protein nitrogen in the photosynthetic apparatus: cost, consequences and control. In: Briggs WR, ed. Photosynthesis. New York: Alan R. Liss Inc., 183-205.

Feller U. 1978. Changes in nitrogen contents and in proteolytic activities in different parts of field-grown wheat ears (Triticum aestivum L.) during maturation. Plant and Cell Physiology 19, 1489-1495.

Feller U. 1990. Nitrogen remobilization and protein degradation during senescence. In: Abrol YP, ed. Nitrogen in higher plants. Somerset: Research Studies Press Ltd, 195-222.

Feller U. 2004. Proteolysis. In: Noodén LD, ed. Plant cell death processes. San Diego: Academic Press, 107-123.

Feller U, Crafts-Brandner SJ, Salvucci ME. 1998. Moderately high temperatures inhibit ribulose-1,5-bisphosphate carboxylase/ oxygenase (Rubisco) activase-mediated activation of Rubisco. Plant Physiology 116, 539-546.

Feller U, Erismann KH. 1978. Changes in gas exchange and in the activities of proteolytic enzymes during senescence of wheat leaves (Triticum aestivum L.). Zeitschrift für Pflanzenphysiologie 90, 235-244.

Feller U, Fischer A. 1994. Nitrogen metabolism in senescing leaves. Critical Reviews in Plant Sciences 13, 241-273.

Feller UK, Soong T-ST, Hageman RH. 1977. Leaf proteolytic activities and senescence during grain development of fieldgrown corn (Zea mays L.). Plant Physiology 59, 290-294.

Fischer A, Feller U. 1994. Senescence and protein degradation in leaf segments of young winter wheat: influence of leaf age. Journal of Experimental Botany 45, 103-109.

Franceschi VR, Giaquinta RT. 1983. Specialized cellular arrangements in legume leaves in relation to assimilate transport and 
compartmentation-comparison of the paraveinal mesophyll. Planta 159, 415-422.

Franceschi VR, Wittenbach VA, Giaquinta RT. 1983. Paraveinal mesophyll of soybean leaves in relation to assimilate transfer and compartmentation. III. Immunohistochemical localization of specific glycopeptides in the vacuole after depodding. Plant Physiology 72, 586-589.

Fröhlich V, Feller U. 1992. Effect of phloem interruption on endopeptidase and aminopeptidase activities in flag leaves of field-grown wheat. Biochemie und Physiologie der Pflanzen 188, $13-21$.

Gebbing T, Schnyder H. 2001. C-13 labelling kinetics of sucrose in glumes indicates significant refixation of respiratory $\mathrm{CO}_{2}$ in the wheat ear. Australian Journal of Plant Physiology 28, 1047-1053.

Gietl C, Schmid M. 2001. Ricinosomes: an organelle for developmentally regulated cell death in senescing plant tissues. Naturwissenschaften 88, 49-58.

Guiamét JJ, Pichersky E, Noodén LD. 1999. Mass exodus from senescing soybean chloroplasts. Plant and Cell Physiology 40, 986-992.

Gutteridge S, Millard BN, Parry MAJ. 1986. Inactivation of ribulose-bisphosphate carboxylase by limited proteolysis. FEBS Letters 196, 263-268.

Herrmann B, Feller U. 1998. $\mathrm{CO}_{2}$, light and temperature influence senescence and protein degradation in wheat leaf segments. Physiologia Plantarum 103, 320-326.

Hildbrand M, Fischer A, Feller U. 1994. Protein catabolism in bean leaf discs: accumulation of a soluble fragment of ribulose1,5-bisphosphate carboxylase/oxygenase under oxygen deficiency. Journal of Experimental Botany 45, 1197-1204.

Hörtensteiner S. 2006. Chlorophyll degradation during senescence. Annual Review of Plant Biology 57, 55-77.

Hörtensteiner S, Feller U. 2002. Nitrogen metabolism and remobilization during senescence. Journal of Experimental Botany 53, 927-937.

Houtz RL, Mulligan RM. 1991. Protection of tryptic-sensitive sites in the large subunit of ribulosebisphosphate carboxylase/ oxygenase by catalysis. Plant Physiology 96, 335-339.

Ishida H, Makino A, Mae T. 1999. Fragmentation of the large subunit of ribulose-1,5-bisphosphate carboxylase/oxygenase by reactive oxygen species occurs near Gly-329. Journal of Biological Chemistry 274, 5222-5226.

Ishida H, Nishimori Y, Sugisawa M, Makino A, Mae T. 1997. The large subunit of ribulose-1,5-bisphosphate carboxylase/ oxygenase is fragmented into $37-\mathrm{kDa}$ and $16-\mathrm{kDa}$ polypeptides by active oxygen species in the lysates of chloroplasts from primary leaves of wheat. Plant and Cell Physiology 38, 471-479.

Ishida H, Shimizu S, Makino A, Mae T. 1998. Light-dependent fragmentation of the large subunit of ribulose-1,5-bisphosphate carboxylase/oxygenase in chloroplasts isolated from wheat. Planta 204, 305-309.

Kato Y, Murakami S, Yamamoto Y, Chatani H, Kondo Y, Nakano T, Yokota A, Sato F. 2004. The DNA-binding protease, CND41, and the degradation of ribulose-1,5-bisphosphate carboxylase/oxygenase in senescent leaves of tobacco. Planta 220, 97-104.

Khan S, Andralojc PJ, Lea PJ, Parry MAJ. 1999. 2' -CarboxyD-arabinitol 1-phosphate protects ribulose 1,5-bisphosphate carboxylase/oxygenase against proteolytic breakdown. European Journal of Biochemistry 266, 840-847.

Klauer SF, Franceschi VR, Ku MSB, Zhang DZ. 1996. Identification and localization of vegetative storage proteins in legume leaves. American Journal of Botany 83, 1-10.
Kokubun N, Ishida H, Makino A, Mae T. 2002. The degradation of the large subunit of ribulose-1,5-bisphosphate carboxylase/ oxygenase into the $44-\mathrm{kDa}$ fragment in the lysates of chloroplasts incubated in darkness. Plant and Cell Physiology 43, 1390-1395.

Kumar PA, Parry MAJ, Mitchell RAC, Ahmad A, Abrol YP. 2002. Photosynthesis and nitrogen use-efficiency. In: Foyer $\mathrm{CH}$, Noctor G, eds. Photosynthetic nitrogen assimilation and associated carbon and respiratory metabolism. Dordrecht: Kluwer Academic Publishers, 23-34.

Luo S, Ishida H, Makino M, Mae T. 2002. $\mathrm{Fe}^{2+}$-catalyzed sitespecific cleavage of the large subunit of ribulose 1,5-bisphosphate carboxylase close to the active site. Journal of Biological Chemistry 277, 12383-12387.

Mae T. 2004. Leaf senescence and nitrogen metabolism. In: Noodén LD, ed. Plant cell death processes. San Diego: Academic Press, 157-168.

Makino A. 2003. Rubisco and nitrogen relationships in rice. Leaf photosynthesis and plant growth. Soil Science and Plant Nutrition 49, 319-327.

Makino A, Sakuma H, Sudo E, Mae T. 2003. Differences between maize and rice in $\mathrm{N}$-use efficiency for photosynthesis and protein allocation. Plant and Cell Physiology 44, 952-956.

Marín-Navarro J, Moreno J. 2006. Cysteines 449 and 459 modulate the reduction-oxidation conformational changes of ribulose 1,5-bisphosphate carboxylase/oxygenase and the translocation of the enzyme to membranes during stress. Plant, Cell and Environment 29, 898-908.

Martinez DE, Luguez VM, Bartoli CG, Guiamet JJ. 2003. Persistence of photosynthetic components and photochemical efficiency in ears of water-stressed wheat (Triticum aestivum). Physiologia Plantarum 119, 519-525.

Minamikawa T, Toyooka K, Okamoto T, Hara-Nishimura I, Nishimura M. 2001. Degradation of ribulose-bisphosphate carboxylase by vacuolar enzymes of senescing French bean leaves: immunocytochemical and ultrastructural observations. Protoplasma 218, 144-153.

Mitsuhashi W, Crafts-Brandner SJ, Feller U. 1992. Ribulose1,5-bisphosphate carboxylase/oxygenase degradation in isolated pea chloroplasts incubated in the light or in the dark. Journal of Plant Physiology 139, 653-658.

Miyadai K, Mae T, Makino A, Ojima K. 1990. Characteristics of ribulose-1,5-bisphosphate carboxylase/oxygenase degradation by lysates of mechanically isolated chloroplasts from wheat leaves. Plant Physiology 92, 1215-1219.

Mulligan RM, Houtz RL, Tolbert NE. 1988. Reaction-intermediate analogue binding by ribulose bisphosphate carboxylase/ oxygenase causes specific changes in proteolytic sensitivity: the amino terminal residue of the large subunit is acetylated proline. Proceedings of the National Academy of Sciences, USA 85, 1513-1517.

Nakano R, Ishida H, Makino A, Mae T. 2006. In vivo fragmentation of the large subunit of ribulose-1,5-bisphosphate carboxylase by reactive oxygen species in an intact leaf of cucumber under chilling-light conditions. Plant and Cell Physiology 47, 270-276.

Nakano H, Makino A, Mae T. 1995. Effects of panicle removal on the photosynthetic characteristics of the flag leaf of rice plants during the ripening stage. Plant and Cell Physiology 36, 653-659.

Nakano H, Muramatsu S, Makino A, Mae T. 2000. Relationship between the suppression of photosynthesis and starch accumulation in the pod-removed bean. Australian Journal of Plant Physiology 27, 167-173. 
Navarre DA, Wolpert TJ. 1999. Victorin induction of an apoptotic/senescence-like response in oats. The Plant Cell 11, 237-249.

Nooden LD, Guiamet JJ, John I. 1997. Senescence mechanisms. Physiologia Plantarum 101, 746-753.

Parrott D, Yang L, Shama L, Fischer AM. 2005. Senescence is accelerated, and several proteases are induced by carbon 'feast' conditions in barley (Hordeum vulgare L.) leaves. Planta 222, 989-1000.

Roulin S, Feller U. 1997. Light-induced proteolysis of stromal proteins in pea (Pisum sativum L.) chloroplasts: requirement for intact organelles. Plant Science 128, 31-41.

Roulin S, Feller U. 1998a. Light-dependent degradation of stromal proteins in intact chloroplasts isolated from Pisum sativum L. leaves: requirement for divalent cations. Planta 205, 297-304.

Roulin S, Feller U. 1998b. Dithiothreitol triggers photooxidative stress and fragmentation of the large subunit of ribulose-1,5bisphosphate carboxylase/oxygenase in intact pea chloroplasts. Plant Physiology and Biochemistry 36, 849-856.

Sage RF, Pearcy RW, Seemann JR. 1987. The nitrogen use efficiency of $\mathrm{C}_{3}$ and $\mathrm{C}_{4}$ plants. III. Leaf nitrogen effects on the activity of carboxylating enzymes in Chenopodium album (L.) and Amaranthus retroflexus (L.). Plant Physiology 85, 355-359.

Salvucci ME, Crafts-Brandner SJ. 1995. Purification and properties of a unique nucleotide pyrophosphatase/phosphodiesterase I that accumulates in soybean leaves in response to fruit removal. Plant Physiology 108, 1269-1276.

Schaller A, Ryan CA. 1995. Cloning of a tomato cDNA (Gen bank L38581) encoding the proteolytic subunit of a Clp-like energy dependent protease. Plant Physiology 108, 1341.

Shanklin J, DeWitt ND, Flanagan JM. 1995. The stroma of higher-plant plastids contain $\mathrm{ClpP}$ and $\mathrm{ClpC}$, functional homologs of Escherichia-coli $\mathrm{ClpP}$ and $\mathrm{ClpA}$ - an archetypal 2-component ATP-dependent protease. The Plant Cell 7, 1713-1722.

Spreitzer RJ, Salvucci ME. 2002. Rubisco: structure, regulatory interactions and possibilities for a better enzyme. Annual Review of Plant Biology 53, 449-475.

Stieger PA, Feller U. 1997. Requirements for the light-stimulated degradation of stromal proteins in isolated pea (Pisum sativum L.) chloroplasts. Journal of Experimental Botany 48, 1639-1645.

Sugiyama T, Mizuno M, Hayashi M. 1984. Partitioning of nitrogen among ribulose-1,5-bisphosphate carboxylase/oxygenase, phosphoenolpyruvate carboxylase, and pyruvate orthophos- phate dikinase as related to biomass productivity in maize seedlings. Plant Physiology 75, 665-669.

Tambussi EA, Bort J, Guiamet JJ, Nogues S, Araus JL. 2007. The photosynthetic role of ears in C-3 cereals: metabolism, water use efficiency and contribution to grain yield. Critical Reviews in Plant Scences 26, 1-16.

Tambussi EA, Nogues S, Araus JL. 2005. Ear of durum wheat under water stress: water relations and photosynthetic metabolism. Planta 221, 446-458.

Thoenen M, Herrmann B, Feller U. 2007. Senescence in wheat leaves: is a cysteine endopeptidase involved in the degradation of the large subunit of Rubisco? Acta Physiologiae Plantarum 29, 339-350.

Thomas H, Ougham H, Canter P, Donnison I. 2002. What staygreen mutants tell us about nitrogen remobilization in leaf senescence. Journal of Experimental Botany 53, 801-808.

Tranbarger TJ, Franceschi VR, Hildebrand DF, Grimes HD. 1991. The soybean 94-kilodalton vegetative storage protein is a lipoxygenase that is localized in paraveinal mesophyll cell vacuoles. The Plant Cell 3, 973-987.

Watson PA, Duffus CM. 1991. Light-dependent $\mathrm{CO}_{2}$ retrieval in immature barley caryopses. Journal of Experimental Botany 42, 1013-1019.

Wirth E, Kelly GJ, Fischbeck G, Latzko E. 1977. Enzyme activities and products of $\mathrm{CO}_{2}$ fixation in various photosynthetic organs of wheat and oat. Zeitschrift für Pflanzenphysiologie 82, $78-87$.

Wittenbach VA. 1982. Effect of pod removal on leaf senescence in soybeans. Plant Physiology 70, 1544-1548.

Yoshida T, Minamikawa T. 1996. Successive amino terminal proteolysis of the large subunit of ribulose-1,5-bisphosphate carboxylase/oxygenase by vacuolar enzymes from French bean leaves. European Journal of Biochemistry 238, 317-324.

Zhang LF, Rui Q, Zhang P, Wang XY, Xu LL. 2007. A novel $51-\mathrm{kDa}$ fragment of the large subunit of ribulose-1,5-bisphosphate carboxylase/oxygenase formed in the stroma of chloroplasts in dark-induced senescing wheat leaves. Physiologia Plantarum 131, 64-71.

Zhang LF, Rui Q, Xu LL. 2006. Degradation of the large subunit of ribulose-1,5-bisphosphate carboxylase/oxygenase in wheat leaves. Journal of Integrative Plant Biology 47, 60-66.

Zhong P-Y, Tanaka T, Yamauchi D, Minamikawa T. 1997. A 28-kilodalton pod storage protein of French bean plants. Plant Physiology 113, 479-485. 